\title{
Spatial distribution of health facilities in Islamabad, Pakistan
}

\author{
M.A. Shaikh
}

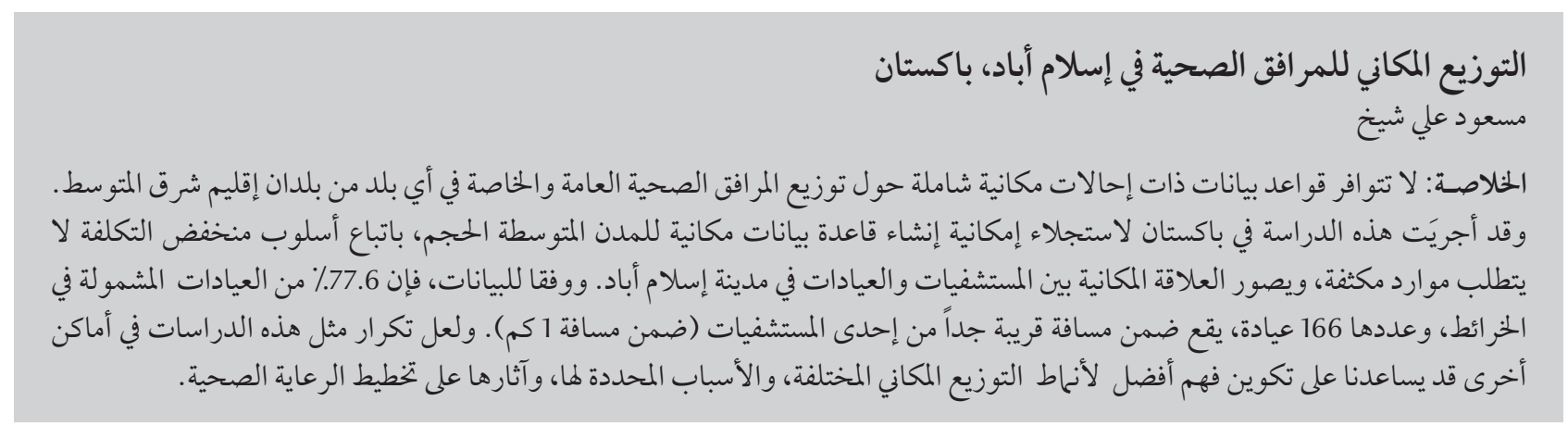

ABSTRACT There are no comprehensive, spatially referenced databases of public and private health facilities in any of the countries of the Eastern Mediterranean Region. This study in Pakistan was conducted to demonstrate the feasibility of creating a spatially referenced health facility database for a medium-sized city, in a low-cost, non-resource intensive manner and to visualize the spatial relationship between hospitals and clinics in the city of Islamabad. Cumulatively, 166 (77.6\% of all clinics mapped) were in close proximity (within $1 \mathrm{~km}$ ) to a hospital. Repeating such studies elsewhere would help us to better understand different spatial distribution patterns, the reasons for them and the implications for health-care planning.

\section{Répartition spatiale des établissements de santé à Islamabad (Pakistan)}

RÉSUMÉ II n'existe pas de bases de données exhaustives référençant la répartition spatiale des établissements de santé publics et privés des pays de la Région de la Méditerranée orientale. La présente étude menée au Pakistan visait à démontrer la faisabilité de la création d'une base de données fournissant les références spatiales des établissements de santé dans une ville de taille moyenne, sur un mode économique et nécessitant peu de ressources pour visualiser les liens spatiaux entre les hôpitaux et les établissements de soins dans la ville d'Islamabad. Au total, 166 établissements de soins cartographiés (77,6 \%) étaient situés à proximité d'un hôpital (moins d'un kilomètre). Reproduire de telles études ailleurs permettrait de mieux comprendre les différentes répartitions spatiales, les raisons motivant ces répartitions et les implications pour la planification des soins de santé. 


\section{Introduction}

Addressing health resource needs is contingent on understanding the distribution of health resources and an assessment of disease burden, and longterm planning in the health sector requires documenting the number, type, and spatial distribution of health facilities for effective decision making $[1,2]$. Geographic information systems (GIS) are increasingly being used for planning of health services in both developed as well as developing countries [2-5].

Islamabad is the capital city of Pakistan, with an estimated population of 1.21 million, in 2009. Various kinds of public and private health facilities exist in the city; however, no tabular or spatial database exists listing such facilities. This lack of baseline data is a major hurdle in implementation of health GIS in many developing countries, including linking of spatially referenced health-facility information with their catchment areas using maps created by using high-resolution satellite imagery in conjunction with census data $[4,5]$.

There are no comprehensive, spatially referenced databases of public and private health facilities in any of the countries of the Eastern Mediterranean Region. This study in Pakistan was conducted to demonstrate the feasibility of creating a spatially referenced healthfacility database for a medium-sized city, in a low-cost, non-resource intensive manner, and to visualize the spatial relationship between hospitals and clinics in the city of Islamabad.

\section{Methods}

Using a recreational-grade GPS unit, the latitude-longitude coordinates of 271 health facilities were collected in the city of Islamabad within a 2-week period from 19-31 July 2011. This covered not only the urban part of the city but the entire Islamabad Capital Territory (ICT) area. All types of health facilities, including public, private, hospitals, clinics and traditional medicine clinics, were covered. Line (vector) maps of the area were not available; so these data were downloaded from the website http://www.OpenStreetMap.org. This vector map was used to display the GPS coordinates of all the health facilities. A map was created to display the collected information and to see the pattern of distribution of health facilities in Islamabad Capital Territory area.

\section{Results}

Cumulatively 271 health-care facilities were identified. There were 58 hospitals in the city (45 public sector/ government hospitals and 13 private hospitals) and 214 clinics (10 public sector/government clinics, 186 private clinics and 18 private homeopathic/ shows the spatial distribution of all these health facilities in the Islamabad Capital Territory area.

A 1-km zone was mapped around the 58 hospitals and all clinics falling traditional medicine clinics). Figure 1

in this zone were counted. Cumulatively, 166 out of 214 clinics $(77.6 \%)$ fell within $1 \mathrm{~km}$ of a hospital.

\section{Discussion}

No comparisons with previous studies could be made since there are no such studies conducted anywhere in Pakistan, or for that matter, in most other developing countries. One possible explanation for this proximity of health facilities to hospitals is that physicians running clinics prefer to have a hospital close by for admitting patients who need inpatient care.

This project was essentially exploratory in nature. Repeating this study after few years might help understand spatiotemporal patterns, i.e. how health-facility distribution patterns changes, if at all, over time. Secondly, repeating this kind of a study in other cities in Pakistan and in other developing countries would help us to better understand different spatial distribution patterns, the reasons for them and the implications for healthcare planning.

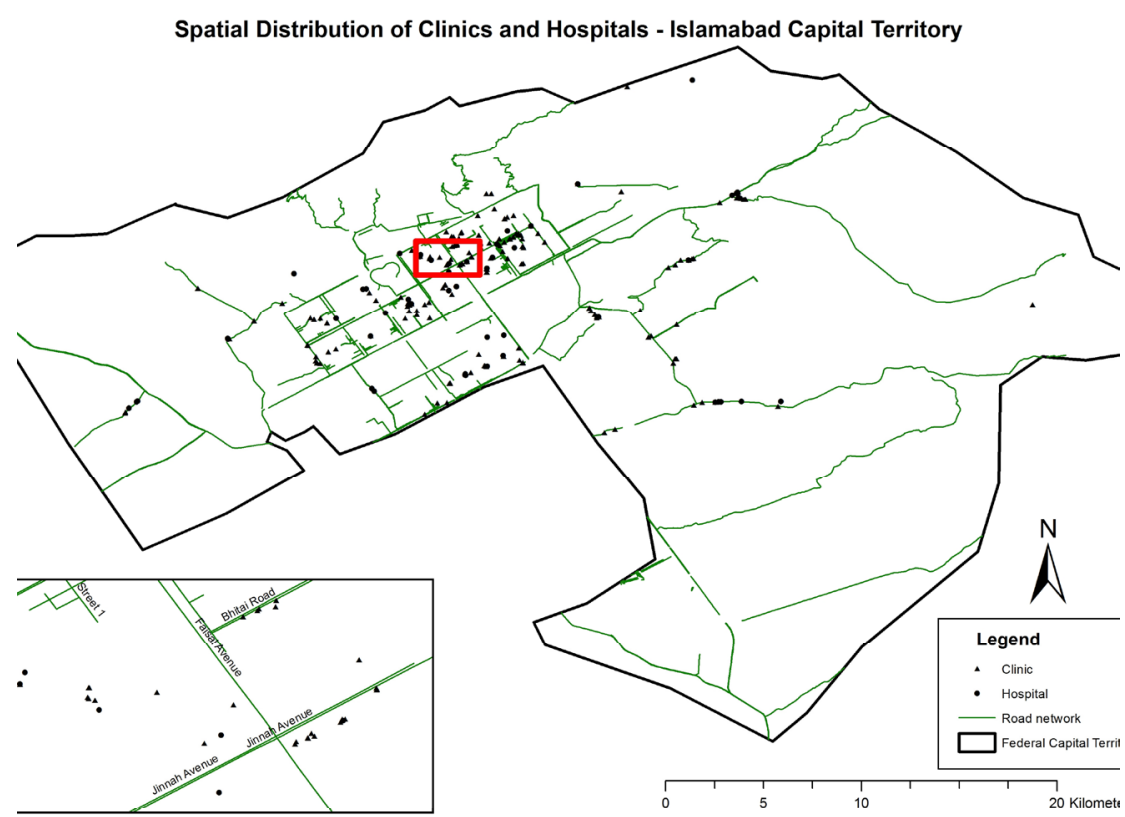

Figure 1 Spatial distribution of health facilities in Islamabad Capital Territory, Pakistan 


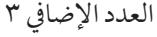

\section{References}

1. Detmer DE. Building the national health information infrastructure for personal health, health care services, public health, and research. BMC Medical Informatics and Decision Making, 2003, 3:1.

2. Bullen N, Moon G, Jones K. Defining localities for health planning: a GIS approach. Social Science and Medicine, 1996, 42:801-816.

3. Noor AM et al. Creating spatially defined databases for equitable health service planning in low-income countries: the example of Kenya. Acta Tropica, 2004, 91:239-251.
4. Ansumana $\mathrm{R}$ et al. Enabling methods for community health mapping in developing countries. International Journal of Health Geographics, 2010, 9:56.

5. Tatem AJ et al. High resolution population maps for low income nations: combining land cover and census in East Africa. PLoS ONE, 2007, 2:e1298. 